\title{
User Preferences in the Design of Advanced Driver Assistance Systems
}

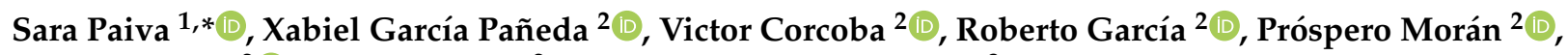 \\ Laura Pozueco $^{2}$ D, Marina Valdés ${ }^{2}$ and Covadonga del Camino ${ }^{3}$ \\ 1 Polytechnic Institute of Viana do Castelo, 4900-367 Viana do Castelo, Portugal \\ 2 Department of Computer Science, University of Oviedo, 33003 Oviedo, Spain; xabiel@uniovi.es (X.G.P.); \\ corcobavictor@uniovi.es (V.C.); garciaroberto@uniovi.es (R.G.); moranprospero@uniovi.es (P.M.); \\ pozuecolaura@uniovi.es (L.P.); valdesmarina@uniovi.es (M.V.) \\ 3 Hospital Universitario Central de Asturias, 33011 Oviedo, Spain; covadongadelcamino@gmail.com \\ * Correspondence: sara.paiva@estg.ipvc.pt
}

Citation: Paiva, S.; Pañeda, X.G.; Corcoba, V.; García, R.; Morán, P.; Pozueco, L.; Valdés, M.; del Camino, C. User Preferences in the Design of Advanced Driver Assistance Systems. Sustainability 2021, 13, 3932. https:// doi.org/10.3390/su13073932

Academic Editor: Hamid R. Sayarshad

Received: 26 January 2021

Accepted: 28 March 2021

Published: 2 April 2021

Publisher's Note: MDPI stays neutral with regard to jurisdictional claims in published maps and institutional affiliations.

Copyright: (c) 2021 by the authors. Licensee MDPI, Basel, Switzerland. This article is an open access article distributed under the terms and conditions of the Creative Commons Attribution (CC BY) license (https:// creativecommons.org/licenses/by/ $4.0 /)$.

\begin{abstract}
The transport network and mobility aspects are constantly changing, and major changes are expected in the coming years in terms of safety and sustainability purposes. In this paper, we present the main conclusions and analysis of data collected from a survey of drivers in Spain and Portugal regarding user preferences, highlighting the main functionalities and behavior that an advanced driver assistance system must have in order to grant it special importance on the road to prevent accidents and also to enable drivers to have a pleasant journey. Based on the results obtained from the survey, we developed and present a working prototype for an advanced driver assistance system (ADAS), its architecture and rules systems that allowed us to create and test some scenarios in a real environment.
\end{abstract}

Keywords: advanced driver assistance system; drivers' preferences; driving safety

\section{Introduction}

Smart mobility is an emerging concept, which will become increasingly relevant in the coming years, and which is aligned with the 17 sustainable objectives defined by the United Nations where sustainability is advocated in the transport network and the emergence of new mobility paradigms. Smart mobility concerns both the transport of goods and people, with our focus being on the transport of people and, in particular, the role that advanced driver assistance systems (ADASs) will play in vehicles in the future, to assist drivers, helping to achieve the maximum level of automation in vehicles.

The acquisition of data from various sensors and other data sources is at the origin of the semi-autonomous vehicles [1] that exist today as well as of the vehicles of the coming years, in which ADAS will still play an important role in helping to guarantee maximum driving safety. It is not just the acquisition of data that needs to be done to power an ADAS and allow it to be an aid tool for the driver. In [2], the processing and evaluation of the collected data are also mentioned as a way to provide a holistic framework. The quality of an ADAS is directly related to the quality of its interaction with the driver [3] and to measured aspects. The functionality of an ADAS can be of varying complexity, from the simple recommendation of braking or even providing cruise control. In reality, the real added value for the driver is in the crossing of data of a different nature (psychological, fatigue, driving style, type of road, time, weather conditions, among others) and in recommendations given to the driver to make driving safer and reduce road accidents.

Autonomous vehicles (AV) will undoubtedly be one of the major changes in terms of mobility in the coming decades, towards the complete (or maximum possible) reduction of the carbon footprint in smart cities. The development that we have been witnessing 
in $\mathrm{AVs}$ is made possible by the automation of tasks and by the proliferation of sensors, with greater and varied functionalities, which allow the monitoring of a set of aspects that contribute to greater equipment autonomy, where AVs are also beginning to be included. In these, the adoption of sensors and their autonomy before the driver has to be taken more seriously compared, for example, to the case of a robot that just cleans, because in the case of a vehicle we are talking about potentially life or death situations. Hence, the adoption of AVs will be progressive. The Society of Automotive Engineers classified AVs in 6 levels [4]. Level 0 has no automation in the vehicle and driving is completely manual. At level 1, some assistance is already given to the driver, such as vehicle braking or cruise control. In level 2, known as Partial Driver Automation, ADAS starts to assume greater relevance and provides drivers with some information in order to assist them in some (still) limited scenarios, such as acceleration or braking, and the driver must maintain constant attention on the road. Up to level 6, there is a progressive decrease in the driver's need for action as the vehicle becomes more autonomous until reaching full automation.

This paper starts by presenting an analysis of data gathered both in Spain and in Portugal, of the user's characteristics, driving behaviors and also functionalities drivers would like to see in an ADAS, so they can perceive it as a real benefit for them while driving. Situations of utmost risk and different alternatives of how to alert the driver have been studied. All this information has been organized in a survey to discover drivers' preferences and driving style. The main purpose of this survey was to collect information on various aspects (psychological, fatigue, road conditions, among others), so that they can be correlated, making it possible to define intelligent rules that can be made available as support for the driver via an ADAS. With the knowledge acquired from the survey, we developed a functional prototype, implemented using a Raspberry-Pi and Python, as a proof-of-concept of how an ADAS can be developed for the purpose of contributing to the safety of drivers, combining different aspects (such as the driving conditions, weather and road conditions or conditions inside the car). The rest of the paper is organized as follows. Section 2 presents the literature related to ADAS, survey designs, interfaces and use-fulness. Section 3 explains in detail the survey design, methodology, obtained results and main conclusions. The developed prototype and test scenarios are explained in Section 4 . Section 5 presents the conclusions and future work.

\section{Literature Review}

\subsection{Review of ADAS}

For the ADAS review, it is particularly relevant for this study research which is related to the effect of ADAS on user behavior and the variety of factors considered for the recommendations provided to drivers. For this reason, the methodology for choosing the papers to carry out this review consisted of a search with the keywords "Driving ADAS/Assistant" and "ADAS/Assistant Driving Behavior", of papers between 2016 and 2021. A first screening of the papers was made based on the presence of keywords considered the most relevant followed by a reading of the pertinent abstract, having chosen the 15 most relevant for this study, from which an analysis is then carried out.

In [5], the authors present an assistant that intends to save fuel costs taking into account the driver's behavior, which is reflected in several ways: how the driver drives, the speed patterns used, the use of the air conditioning or the choice of route. The authors claim that all of these factors have an influence on safety when driving. In [6], the authors propose a system that takes into account road slope, curvature, superelevation, speed limits and traffic signs to send recommendation messages to the driver in order to release the accelerator and thus save more energy and increase comfort and driving safety. In [1], the authors present a proposal that collects data from various sources (On-Board Diagnosis (ODB) sensors, GPS, Inertial Measurement Units (IMU)) in order to carry out studies on the driver's behavior, thus facilitating fuel and cost savings, correlating flaws in the car with the driving style. 
In [7], the authors propose a system that aims to combat possible accidents based on the driver's drowsiness, monitoring when the driver involuntarily changes lanes. The system makes a first correction so that the vehicle remains parallel to the lane departure and, if there is no reaction from the driver (the system inferring that the driver is asleep), then the assistant carries out the correction itself, placing the vehicle in the center of the lane. The monitoring of the driver is in order to understand the driver's reaction when the vehicle starts to change lanes, changes direction and/or brakes. Based on the reaction of the driver, the assistant concludes, on a scale of 5 levels, the degree of drowsiness of the driver. In [8], the authors present the proposal for an ADAS that aims to detect the driver's fatigue/drowsiness through an image recognition method, focusing on the state of the driver's eyes.

In [3], the authors study the behavior of drivers in the face of a possible collision scenario and monitor their reactions in order to conclude the best behavior of an ADAS in these situations. One of the conclusions of the study is that the driver will be more receptive to warnings from an ADAS about possible collisions when it is lateral and less receptive when it is frontal. It is also considered important that the ADAS has access to data such as the predicted time until the collision, the outside time, the speed at which obstacles move, the space that the driver has available to maneuver, the degree of ease with which the driver can detect whether the road has potential hazards and whether the driver is alert or distracted. Although the authors refer to the importance of these parameters, the proposed system does not provide for their use or any way to detect them. In [9], the authors use artificial neural networks to propose an intelligent recommendation system for drivers, especially in areas where there is a greater risk of accidents. The system is based on the recognition of the outer area based on maps, rather than on driver monitoring. In [10], the authors address critical factors such as weather and lighting, fundamental aspects for road detection and vehicle recognition, necessary in an ADAS to provide the drivers with accurate recommendations. The better the recognition of the road and the traffic surrounding the vehicle, the better the safety recommendations that the ADAS can offer and, if necessary, take control of the vehicle in dangerous situations. Based on the level of street lighting, an ADAS with the described characteristics can recommend the most appropriate speed as well as the lighting that the vehicle should activate. There is no monitoring in this study of another type of situation more related to the drivers themselves. In [11], the authors present a study with two main features of ADAS. One is Adaptive Cruise Control, which allows the vehicle to maintain a safe distance to the vehicle in front, using two scanning sensors modeled in PreScan for this purpose. The other feature is the Autonomous Intersection Crossing which aims to avoid collisions at intersections when vehicles are moving perpendicular to each other. The process uses a feedback map and a collision detection algorithm that may involve the vehicle's automatic braking system. In [12], the authors propose an assistant that helps the driver in making a left turn at an intersection, providing information on vehicles approaching from the right side. The system makes use of a LIDAR sensor to obtain the necessary traffic information to provide the driver, through a dialogue component, which is also part of the system and is the main form of interaction with the driver.

In [2], the authors propose a holistic framework that does the acquisition and processing of vehicle data. The acquisition is carried out through several sensors and the data is processed on the server, where it is possible to gather tracking information and road characteristics and associate statistical metadata. In [13], the authors present the GIS platform-GPS-GIS Integrated System for Travel Time Surveys-which uses GPS data combined with a Geographic Information System (GIS), collecting traffic information based on the speed of probe vehicles and, thus, estimating travel times both statically and dynamically.

In [14], the authors focus on the drivers' assessment with regard to their driving style, more specifically monitoring the position of their arms in relation to the steering wheel, in order to draw conclusions on the drivers' behavior and driving style. In [15], 
the authors aim to measure the impact of an ADAS according to the driver's experience. The information collected includes drivers' behavior, vehicle kinematics and vehicle surroundings. More specifically, the system gathers data on the headway and lane position, vehicle surroundings using a video camera, acceleration, latitude and longitude of the vehicle, its speed, acceleration, braking and steering wheel movement angle. The main results of the study showed that the ADAS had a more positive effect on drivers with less experience. In [16], the authors study the contribution of three aspects-driver, vehicle and lane attributes-as a means of the identification of signs of dangerous driving. For this purpose, they monitor the various aspects collected from different data sources: vehicle speed, land slope, lane departure, following distance, respiratory rate, driver attention, heart rate, mood, speed limit, traffic flow, road type, weather, etc. The authors present a layer of inference that correlates the different aspects in order to be able to conclude about the degree of danger of the driver's driving style. The authors do not, however, explore the type of recommendations that should be given to the driver in order to drive more safely and reduce the likelihood of an accident. In [17], the authors propose a system that aims to improve driving when predicting events on the road from values obtained through sensors. Recommendations are given to drivers through voice commands to assist the driver in complex driving scenarios. The authors state that the assistant represents a companion for the driver and that it represents emotional stability. In [18], the authors present a model based on artificial neural networks in order to classify the state of the driver in three levels: aggressive, normal and calm. It is argued by the authors that the driver's condition directly influences vehicle control as well as energy efficiency. The authors propose to analyze driving patterns so that the results can help in the proposal of an ADAS. For this study, three inputs are used: vehicle acceleration, speed and accelerator pedal angle.

ADASs, when interacting with drivers, end up indirectly having consequences in terms of traffic congestion itself, as drivers' driving patterns and their characteristics (operate, vision, physical and psychological characteristics) are decisive factors in the fluidity of road traffic [19]. If an ADAS perceives the state of the driver and manages to calm him down and lead to a state where he can drive calmly, it will have consequences for traffic at various levels, including congestion or accidents. In [20], the authors study the effect of aggressive driving on urban traffic, namely on the behavior of drivers at intersections with and without signs. The study concluded that there is a noticeable greater tendency for rules to be violated at intersections without signposts. In [21], the authors demonstrate some experiments that show the effect of the topology of the streets as well as the behavior of drivers in traffic and propose a model to describe the phase of transition from normal traffic to a situation of congestion. As a future work, the authors refer to the importance of developing methods to change the behavior of the driver so that the transition phase to a state of congestion is smoother.

Regarding commercial solutions, vehicle manufacturers are incorporating driving assistants focused on safety and fuel consumption. Tesla is one of the most relevant manufacturers in the use of these technologies. Its vehicles have a system denominated "Auto-Pilot" that allows semi-automatic driving [22]. Nissan has developed Propilot Assist 2.0 [23], a system that maintains the vehicle in the middle of a lane and automatically respects the safety distance. In addition, its vehicles also include solutions to detect drowsiness and improve driving style based on telemetry [24].

Another proposal that stands out in this research field is BMW's intelligent personal assistant [25]. This assistant obtains information such as the level of driving efficiency, the nearest petrol station or the route to reach a destination. In addition, the user can indicate if they feel tired. In this case, a vitality program is triggered to adjust the car's lighting, music and temperature to make the driver feel more awake. The problem is that the driver is the one who has to proactively report his/her state. In conclusion, commercial solutions make very limited used of information about the driver's state (emotions, feelings, physiological signals) and driver's preferences, as well as of the vehicle cabin. Moreover, their cost is 
very high due to the need to add cameras and sensors. For this reason, they are not usually part of the vehicle's basic equipment.

The main objective of the analysis carried out on some of the most recent studies on ADAS is to establish what kind of variables are being considered to make recommendations to drivers. The studies analyzed can be summarized in 4 main categories, taking into account their objectives, and can be seen in Table 1. It is possible to conclude that the study presented in [16] is the most complete and comprehensive from the point of view of the parameters considered, taking into account different factors (driver, road, weather and vehicle). However, the study makes no reference to how the rules affect the recommendations to the driver.

Table 1. Main purpose of the advanced driver assistance system (ADAS) studies analyzed in the literature review.

\begin{tabular}{lc}
\hline \multicolumn{1}{c}{ Goals } & Studies \\
\hline Save fuel costs/energy & {$[1,5,6,18]$} \\
Collision/Accident risk detection & {$[3,9-12,16]$} \\
Fatigue/drowsiness detection & {$[7,8]$} \\
Study driving patterns & {$[1,2,13-21]$} \\
Commercial solutions & {$[22-25]$} \\
\hline
\end{tabular}

\subsection{Review of Survey Designs}

The relevance and pertinence of gathering feedback from the users' preferences is fundamental before an ADAS is introduced into the market [26]. Among these preferences we can find those concerned with human-computer interaction, controllability, attention or efficiency and many studies exist on several aspects of driving [27-29]. In the state-of-theart, there are many works dedicated to identifying the risk factors that affect the accident exposure rate (kilometers travelled in a year by drivers) and the risk of suffering a traffic accident. In this research, we use surveys in order to discover aspects associated with these two questions and that include personality, driving experience, distractions, driving mistakes, etc. Our first step has been to review the studies published on typical keywords in these studies such as driving questionnaires, driving scale behaviors and attitudes, driver's behavior patterns and young drivers. The latest bibliographical review carried out in Spain focused on drivers of 4-wheel motor vehicles as a target population [30]. This work excluded the questionnaires about physical aptitudes of the driver (based on physical tests) or psychological characteristics (based on psychometric tests). This opens a wide field of study that fits in with our research aspirations. Another work [31], continuation of an earlier study, is used as the starting point for the questionnaire initially proposed in our project. In this research, the authors propose a questionnaire named mobility, traffic accidents and associated circumstances (MATCA) based on [32]. It is focused on the frequency of involvement in driving circumstances theoretically associated with traffic accidents among the university population. However, it presents a good number of questions perfectly adaptable to our objective of detecting situations in which the user is affected by the environment in which they drive. We have taken into account different references from the MATCA questionnaire, which is defined as easy to complete, with special attention being paid to the driving frequency, an issue of interest for our project, and the accident rate. This questionnaire consists of five sections, some of which, in their correct formulation, are very useful for our research.

1. Socio-demographic data: crucial to contrast the social features of drivers on which to apply our assistance analysis to the driver.

2. Assessment of the use of the car in the previous year (measured in $\mathrm{km} /$ year).

3. Frequency of use of protection devices (belt and helmet) in the previous six months. This information is not useful for our purposes.

4. Involvement in traffic accidents during the previous year (indicating the number and characteristics of the last traffic accident suffered). 
5. Age of obtaining driving license (car or motorcycle), two questions about their quality as a driver and their perceived driving speed and a set of 28 dichotomous response questions, presented in the form of a matrix, which is related to driving circumstances potentially associated with accidents.

This last section is the most interesting and, therefore, offers us the most questions for implementation in our study. We have verified that most of the studies which have explored the frequency of involvement of drivers in risky driving behaviors, generally use very long and complex questionnaires, with many items (normally between 50 and 70). In addition, the scoring scales are also complex. Another problem is that the surveys contain questions about behaviors that are difficult to remember after a certain time. Furthermore, they do not take into account important issues for the characterization of drivers such as the number and distance of the trips. The reason is that most surveys are based on the Driving Behavior Questionnaire (DBQ) mentioned in [33], the most frequently used questionnaire worldwide (and the only questionnaire validated in Spain about risky driving behaviors), which does not include information about driving exposure among its items.

Another of the references for our questionnaire is [34]. This proposal is based on Theory of Planned Behavior (TPB) [35] which has been applied along with Driving Style Questionnaire or Driving Behavior Questionnaire (DBQ) and Depression Anxiety Stress Scales (DASS) [36] with the aim of evaluating its performance in a sample of real drivers. This work is very interesting because it discusses the suitability of the psychological measuring instruments used in the study of driving behavior. The capacity of such instruments is analyzed in the light of their reliability, validity, ease of use and practical convenience in order to use them in studies of transport psychology in the Latin American environment.

In addition, this questionnaire was translated into Spanish. Then a bilingual psychologist, with experience in translation and without previous knowledge of the scales, translated it from Spanish into English. The next step was to give the two English versions of each scale to a group of three people whose native language is English to detect possible qualitative differences between versions. In the case of the TPB questionnaire, an initial version was developed directly in Spanish that was analyzed critically by a group of five psychologists with experience in developing tests. After discussing and making the corrections requested, it was evaluated by three young men and women, aged between 20 and 25, who also made qualitative observations regarding the instrument. After this step, a final version of the work was revised. Finally, we have also considered other works when preparing our questionnaires such as Nasa Task Load Index (Nasa-TLX) [37] and (Driving Activity Load Index) DALI [38]. These proposals are focused on measuring the workload. This technique has been validated in different scenarios, obtaining good results $[39,40]$. Its main advantage is that it is non-intrusive and the fact that it is able to quickly ascertain the cause of the workload. Workload and traffic accidents have a strong relationship. Traffic accidents may be due to incorrect perception, lack of attention or inadequate information processing. This usually happens when the drivers' workload is either very high or very low.

\subsection{Review of Interfaces and Usability}

Whereas human-to-human communication is progressively being replaced by humanto-computer interaction, we are witnessing to the growing trend of applying virtual assistants for several purposes [41]. An ADAS has great potential to increase the safety of drivers. The effectiveness of this goal will be maximized if the interaction and communication between driver and the ADAS is optimized. For that reason, human-centered design principles must be considered [42]. Avatars can take the human form and should be designed according to the user's preferences and characteristics (such as gender, ethnicity, culture, language or others), so the user can feel more comfortable interacting with the avatar $[42,43]$. Some avatars use the robot form, others allow the upload of a design the user likes [44] and others provide the user with the option of choosing an avatar from a list of existing possibilities [42]. In most cases, avatars use a 3D-look only by showing the 
face or upper-body. For avatar design, and if it takes a human form, the avatar should consider aspects such as the skin color, facial proportions and features so that the user feels identified with the avatar. Along with the dialogue, the avatar can also use facial expressions that demonstrate the most common feelings (happiness, boredom, sadness, etc.) that appear in conversation. Additionally, the user experience should be as close as possible to a conversation between two people in terms of fluency and speech. The speech mode should adapt to the characteristics of the user, in terms of the speaking style (which is different from young to old, for example) and words used. In this way, better results are achieved in terms of changes in the attitude than those obtained with generic messages and not dependent on user characteristics.

One of the main goals that an avatar must fulfil is to create empathy with the user. Empathy is seen, in a psycho-therapeutic context, as fundamental to achieve positive changes [42] in a person's behavior and attitudes, hence the reason why the avatar should be able to captivate the user in terms of appearance and speech. To promote avatar adaptability, the avatar can be explicitly chosen by implicit characteristics of the user. On the one hand, characteristics can be explicitly selected by the user and may include gender (man or woman, since the style of conversation is different) or name (use speech that includes the name to be more personalized). On the other hand, the avatar can implicitly infer user preferences collected in a non-intrusive way during the interactions. In some cases, the avatar can directly ask the users what goals they want to achieve and tailor recommendations to help achieve them [42]. Using an avatar to communicate with the user can reduce stress and improves concentration [45]. This is very important in driving because tension increases the likelihood of making mistakes and, therefore, traffic accidents [46]. The interaction of the user with the system must take into account the driving context. Obviously, focusing the user's attention on a visual element only, whether it is shown on a Head-Up Display (HUD) or on a Head-Down Display (HDD), while driving is not the most appropriate [47]. For this reason, another element of interaction with the driver is defined based on sound alerts. This type of alerts has proved very effective, especially in emergency situations [48]. Studies reveal that auditory messages are more intrusive and difficult to ignore, and the reaction time is shorter, while visual messages require more processing and reaction time [49]. In the context of driving, it is also important that the sound is not annoying, so the auditory messages must be defined correctly so that the driver can quickly interpret what is being referred to, without needing to seek visual support to interpret the signal [50]. Other proposals in this regard include both approaches: sound alerts in conjunction with visual messages. Obviously, this approach will improve the efficiency of human-machine interaction, as well as avatars. A third method of interaction with the user is through the vibration of certain elements in contact with the driver. In this aspect, the literature generally considers this third type of interaction with the user as redundant, used mainly as support for other types of signals (acoustic or visual) [51]. According to studies such as [52], as the number of warning signals to the driver increases (only visual, visual + sound, visual + sound + haptic signal), reaction times are faster. Therefore, depending on the degree of emergency of the warning to be given to the driver, we can differentiate between a message through a single stimulus, two or even three in the most urgent cases. Not only is the way in which the information is presented important, either visually or acoustically, but a key factor of interface design is also related to the perception that the user has of the system. For instance, if the frequency with which the driver interacts is too high, this can cause an excessive need for attention by the driver and may even undermine the acceptance of the system [53]. In the design of the interface, therefore, the frequency with which the driver interacts should be taken into account, since it is a factor that may be closely related to confidence in the system. If the driver considers that the alert is unnecessary or annoying, the use of the interface may be ignored, rendering the driving assistance system useless. In addition, it is important that the ADAS and the driver maintain an adequate level of interaction, without reaching the point that the driver ignores the messages generated by the system or becomes too 
aware of the system to such a degree that decreases the level of attention on the road. Therefore, attention should be placed on the design of the interface, but a correct design of interaction and communication with the user is also crucial to avoid this type of situation. In all cases, the ADAS design must be kept simple. If the user has to consult a manual while driving, the workload increases significantly, and the driving performance decreases. The management of the ADAS should not require the use of a manual, or in any case, help should be offered through a voice interface [47]. In 2011, Audi engineers, in cooperation with scientists at the Technische Universitaet Muenchen developed what they called an Avatar-based Virtual Co-driver System (AviCoS), with the main purpose of replacing the manual text, instead delivering it to the driver using an assistant that is more user-friendly and intuitive to use [54]. The avatar, a virtual figure that understands complete sentences, uses AI to process drivers' questions and to display answers and relevant information. In order to avoid the driver becoming distracted as the speed increases, the images and animations are suppressed, switching solely to audio information. In 2017, a study by IBM Research described a system that interacts with the driver and takes into account contextual information from outside the car (the environment, information about congestion, local regulations, traffic restrictions, etc.) and also about the driver (current actions, history, usual trips undertaken, time of day), to identify potential risky situations and warn the driver to mitigate risks $[54,55]$. The company Charamel integrated Carla, an avatar, into a radio navigation system for a Volkswagen AG. The main goal was to explain the functionality of the RNS810 navigation system [56]. The same company developed a virtual assistant for the MyFord Touch Guide app for Ford. The avatar developed for Mercedes can react not only based on active input of the user, but also through acoustic alert signals with additional information [57]. During CES 2019, the world's largest consumer tech show, Nissan presented the concept "invisible-to-visible", a system to be incorporated in cars that gathers data from the cloud and the car itself and combines them to create a visualization to aid drivers. One functionality was detecting pedestrians, via sensors and cloud mapping services, that may be unnoticed by drivers due to weather conditions or distractions. Nissan proposed an animated avatar that mainly provides recommendations for the driver using a Head-Up Display [58].

\section{Survey Design, Analysis and Results}

In this section, we describe the survey we have carried out in order to determine characteristics of the drivers, their behaviors and what they look for in a driving assistant (type of warnings and recommendations, frequency in issuing recommendations and user interaction). The questions included in the survey can be classified into 8 sets according to the topic they address: (1) characteristics of the drivers, (2) work-related stress, (3) driver lifestyle, (4) vehicle features and main use, (5) driving behaviors, (6) driving distractions, (7) driving stress and (8) driving assistant.

\subsection{Analysis Methodology}

An analysis will be carried out by country, age and gender in order to detect associations between personal characteristics and the aspects under study. For the analysis by age, three age ranges have been defined between the maximum and minimum values of the respondents: aged 18 to 40,41 to 60 and 61 to 80 , respectively.

Fisher and Pearson Chi-squared tests [59] have been performed in order to determine associations between categorical variables. Pearson Chi-squared test or Fisher's tests are used depending on whether the hypothesis about expected frequencies is verified or not. In order to apply the Chi-squared test, the expected frequencies must be greater than 5 in at least $80 \%$ of cases. If this is not met, then Fisher is applied. Fisher and Chi-squared tests return the decision of the null hypothesis that there are no non-random associations between the two categorical variables, against the alternative that there is a non-random association. Both tests return the significance level of the test $p$-value in order to determine 
if the test rejects the null hypothesis at the $5 \%$ significance level, or not. In both tests, if $p$-value is under 0.05 there is association between the two variables.

\subsection{General Characteristics of the Participants}

A total of 888 surveys were conducted in Spain (704 respondents) and Portugal (184 respondents). In order to recruit the respondents, a call was made for volunteers both in Spain and Portugal through the Internet. Of all the participants, $18.2 \%$ were aged $18-30$, $22.6 \%$ were aged $31-40,36.5 \%$ aged $41-50,16.7 \%$ aged $51-60,5.4 \%$ aged $61-70$ and $0.6 \%$ were aged $71-80$. Regarding gender, $51 \%$ were men and $47 \%$ women (the others indicated no gender). Of the respondents, $64 \%$ have never used a virtual assistant, $30 \%$ have used one and $6 \%$ do not know what it is. In addition, $91 \%$ of the respondents have university studies and $9 \%$ secondary studies. When asked if they enjoy driving, $74 \%$ answered positively, $9 \%$ negatively and the others chose "usually" or "hardly ever". Finally, regarding skills, the most significant include sciences (30\%), communication (26\%) and engineering $(24 \%)$.

\subsection{Usefulness of an ADAS}

In this section, we analyze the answers of the participants about the usefulness of the assistants. The goal was to gather information about the perception of usefulness of the assistant by drivers who do not have an ADAS and how it is used by those who already have one. Of all the respondents, 590 (66\%) do not have a driving assistant, while 298 $(33 \%)$ do.

\subsubsection{Drivers without an ADAS}

The answers to the question "Would it be useful to have a driving assistant?" are indicated in Table 2. In general, only $7.8 \%$ of respondents do not see any usefulness of the assistant. The rest consider it useful, especially if they are going to drive through unknown areas (64.1\%). These results are independent of the country or gender of the drivers. However, the results indicate that there is an association between the perception of usefulness of the ADAS and the age of the drivers. These differences in the acceptance of new technologies in vehicles are also highlighted in the research in [60-62].

Table 2. Usefulness of the ADAS: General responses from drivers that do not use an ADAS.

\begin{tabular}{lcc}
\hline \multicolumn{1}{c}{ Questions } & Frequency & \% \\
\hline I know what it is, but it does not seem useful & 46 & 7.8 \\
I do not know what it is & 12 & 2.0 \\
Yes, under any circumstance & 131 & 22.2 \\
Yes, when driving in the city & 23 & 3.9 \\
Yes, when driving in unknown zones & 378 & 64.1 \\
Total & 590 & 100.0 \\
\hline
\end{tabular}

In our study, the tests show significant differences in the perception of the usefulness of ADAS by age, as shown in Table 3, which represents the association between age and ADAS usefulness (Fisher test: $p$-value $=0.043$ ). Thus, people under the age of 40 and between the ages of 41 and 60 show a more positive predilection ( $89 \%$ and $91 \%$, respectively) towards aid systems than those over the age of $60(81 \%)$. These results contradict previous studies such as [62-65]. The explanation, in this case, may be due to the fact that they are drivers without a driving assistant. Older people are more unaware (6\%) and distrustful (12\%) of new technologies, which causes a decrease in the positive attitude towards the usefulness of these systems. 
Table 3. Usefulness of the ADAS: Responses by age from drivers that do not use an ADAS.

\begin{tabular}{lcccccc}
\hline \multirow{2}{*}{ Questions } & \multicolumn{2}{c}{ Age under $\mathbf{4 0}$} & \multicolumn{2}{c}{ Age 41-60 } & \multicolumn{2}{c}{ Age over 60 } \\
\cline { 2 - 7 } & $\mathbf{n}$ & $\mathbf{\%}$ & $\mathbf{n}$ & $\mathbf{\%}$ & $\mathbf{n}$ & $\mathbf{\%}$ \\
\hline I know what it is, but it does not seem useful & 24 & 9.41 & 20 & 6.62 & 2 & 6.06 \\
I do not know what it is & 3 & 1.18 & 5 & 1.66 & 4 & 12.12 \\
Yes, under any circumstance & 56 & 21.96 & 67 & 22.19 & 8 & 24.24 \\
Yes, when driving in the city & 6 & 2.35 & 16 & 5.30 & 1 & 3.03 \\
Yes, when driving in unknown zones & 166 & 65.10 & 194 & 64.24 & 18 & 54.55 \\
\hline
\end{tabular}

\subsubsection{Drivers with an ADAS}

Different questions about driving needs and preferences will be analyzed for drivers who have a driving assistant.

\section{Usefulness of the ADAS}

When asked "Do you find the driving assistant in your vehicle useful?", 95.3\% of the respondents consider ADAS quite or very useful. The Pearson Chi-squared test indicates no differences by country, gender or age.

\section{When It Is Useful to Have an Assistant}

As for the question "When do you find it useful to have a driving assistant?", most drivers make use of the assistant when driving through unknown areas $(74.5 \%)$, under any circumstance $(17.1 \%)$ and when driving in the city $(6.4 \%)$. There are no differences by country ( $p$-value $=0.609)$ or by age ( $p$-value $=0.217)$. However, there are differences by gender ( $p$-value $=0.003$ ). Thus, in the case of women, the percentage that indicates that it is useful when driving in unknown areas increases to $85 \%$, compared to $67 \%$ of men.

Aspects of Improvement of the Assistant

The answers to the question "What aspects of your vehicle's driving assistant would you improve?" are indicated in Table 4. Drivers with an assistant propose some improvements in the design. The most significant correspond to improvements in the interaction and notifications. In the case of improvements in interaction there is a clear association with the age of the drivers. Thus, $62 \%$ of younger drivers would improve the interaction with the system, while in the other groups the percentage is around $40 \%$. This significant difference may be due to a greater familiarity of younger people with the new technologies, which makes them more demanding and critical of this type of systems. There is also a significant difference by gender in terms of improving the interface. A total of $30 \%$ of men suggest improvements in this aspect, doubling the percentage of women who suggest improving the interface $(15 \%)$.

Table 4. Areas for improvement of ADAS.

\begin{tabular}{lccccc}
\hline \multirow{2}{*}{$\begin{array}{c}\text { Area for Improvement } \\
\text { of ADAS }\end{array}$} & \multicolumn{2}{c}{ General Scores } & \multicolumn{2}{c}{ Pearson Test $(p$-Value) } \\
\cline { 2 - 6 } & Frequency & $\mathbf{\%}$ & Country & Gender & Age \\
\hline Notifications & 150 & 50.3 & 0.197 & 0.550 & 0.884 \\
Interaction & 149 & 50.0 & 0.881 & 0.265 & 0.007 \\
Information & 84 & 28.2 & 0.619 & 0.287 & 0.072 \\
Interface & 71 & 23.8 & 0.506 & 0.003 & 0.345 \\
\hline
\end{tabular}

\subsection{Assistant Design Preferences}

In this section, we will analyze the needs and preferences of users regarding several aspects to consider in the design of an ADAS. The following tables show the results for drivers with and without ADAS differentiated by country, gender and age, indicating the statistic $p$-value in each case to determine associations between the variables. 


\subsubsection{Frequency of Warnings or Recommendations}

When designing an ADAS, it is important to determine when warnings or notifications are sent to the driver. The preferences of the respondents to the question "How often would it be appropriate for you to receive warnings or recommendations?" about the frequency of the notifications are indicated in Table 5, where $\mathrm{n}$ indicates the number of responses and $\%$ the percentage of responses.

Table 5. Responses of the participants referring to the frequency of notifications.

\begin{tabular}{lcccc}
\hline \multirow{2}{*}{ Notification Frequency } & \multicolumn{2}{c}{$\begin{array}{c}\text { Respondents without } \\
\text { ADAS (N = 590) }\end{array}$} & \multicolumn{2}{c}{$\begin{array}{c}\text { Respondents with } \\
\text { ADAS (N = 298) }\end{array}$} \\
\cline { 2 - 5 } & $\mathbf{n}$ & $\mathbf{\%}$ & $\mathbf{n}$ & $\mathbf{\%}$ \\
\hline When there is relevant information & 461 & 78.10 & 233 & 78.20 \\
When driving tired & 99 & 16.80 & 49 & 16.40 \\
When there are traffic accidents & 95 & 16.10 & 51 & 17.10 \\
When there are adverse weather conditions & 83 & 14.10 & 43 & 14.40 \\
When approaching a dangerous zone & 76 & 12.90 & 33 & 11.10 \\
When approaching heavy traffic & 63 & 10.70 & 32 & 10.7 \\
When speed limits are exceeded & 62 & 10.50 & 33 & 11.10 \\
Continuously & 43 & 7.30 & 31 & 10.4 \\
When approaching roadworks & 40 & 6.80 & 18 & 6 \\
When approaching pedestrian zones & 29 & 4.90 & 25 & 8.4 \\
Minutes & 29 & 4.9 & 22 & 7.4 \\
Fixed periods & 29 & 4.9 & 22 & 7.4 \\
Per itinerary & 25 & 4.2 & 10 & 3.4 \\
When approaching schools & 25 & 4.20 & 16 & 5.4 \\
\hline
\end{tabular}

In this aspect, $78 \%$ of all respondents, with or without a driving assistant, prefer to receive ADAS alerts when there is relevant information to report. This response is independent of the country, gender or age of the participants. It is important to highlight that users do not want periodic or programmed notifications or with temporary programming but prefer alerts when an exceptional or dangerous situation occurs.

\subsubsection{Information on Traffic}

The answers to the question "Which of the following information regarding traffic would you like to receive through the assistant?" are shown in Table 6. Observing the answers, in more than $50 \%$ of the cases the drivers without ADAS prefer to receive information about nearby accidents, traffic jams, dangerous areas of the road and driving in a prohibited direction. The rest of the options are marked in less than $50 \%$ of the cases. The trend is similar for participants who already have ADAS, which gives a notion about what users prefer to be notified about in terms of driving.

\subsubsection{Information on Driving}

The preferences of the respondents regarding the question "Which of the following information regarding your driving would you like to receive through the assistant?" are shown in Table 7 . Drivers do not wish to receive information stating that they are smoking while driving. On the other hand, more than $50 \%$ of drivers want to be notified when they start to feel tired $(60 \%)$ and when they exceed the maximum speed limit $(50 \%)$. The results are practically the same for drivers with ADAS. There are two notable associations per country for users with ADAS. While in Portugal $51 \%$ of drivers prefer to be warned about over-aggressive driving, in Spain the figure drops to $29 \%$. Regarding alerts about air quality, $60 \%$ select this option in Portugal compared to $33 \%$ in Spain. 
Table 6. Responses of the participants referring to the traffic and roads.

\begin{tabular}{lcccc}
\hline \multirow{2}{*}{$\begin{array}{c}\text { Information Provided by ADAS } \\
\text { Appondents without }\end{array}$} & \multicolumn{2}{c}{$\begin{array}{c}\text { Respondents with } \\
\text { ADAS (N = 590) }\end{array}$} & \multicolumn{2}{c}{ ADAS (N = 298) } \\
\cline { 2 - 5 } & $\mathbf{n}$ & $\mathbf{\%}$ & $\mathbf{n}$ & $\mathbf{\%}$ \\
\hline Approaching an accident & 400 & 67.80 & 214 & 71.80 \\
Approaching a traffic jam & 387 & 65.60 & 193 & 64.80 \\
Driving in a forbidden direction & 368 & 62.40 & 192 & 64.40 \\
Approaching a dangerous section of road & 320 & 54.20 & 172 & 57.70 \\
Approaching roadworks & 271 & 45.90 & 138 & 46.30 \\
Approaching out of order traffic lights & 267 & 45.30 & 118 & 39.60 \\
Approaching a heavy traffic zone & 254 & 43.10 & 152 & 51.00 \\
Approaching dangerous curves & 241 & 40.80 & 122 & 40.90 \\
Approaching a wild animal zone & 210 & 35.60 & 98 & 32.90 \\
Approaching an area with a high density & 206 & 34.90 & 109 & 36.60 \\
of pedestrians & 188 & 31.90 & 106 & 35.60 \\
Approaching a school zone & & &
\end{tabular}

Table 7. Responses of the participants referring to their driving.

\begin{tabular}{lcccc}
\hline \multirow{2}{*}{$\begin{array}{l}\text { Information Provided by ADAS } \\
\text { Atarting to suffer from fatigue/tiredness }\end{array}$} & $\begin{array}{c}\text { Respondents without } \\
\text { ADAS (N = 590) }\end{array}$ & \multicolumn{2}{c}{$\begin{array}{c}\text { Respondents with } \\
\text { ADAS (N = 298) }\end{array}$} \\
\cline { 2 - 5 } & $\mathbf{n}$ & $\mathbf{\%}$ & $\mathbf{n}$ & $\mathbf{\%}$ \\
\hline Exceeding the maximum speed limit of & 296 & 60.30 & 199 & 66.80 \\
the road & 215 & 50.20 & 153 & 51.30 \\
Not keeping the safety distance & 220 & 36.40 & 117 & 39.30 \\
Driving erratically & 200 & 33.90 & 132 & 44.30 \\
The air quality is not appropriate & 189 & 32.00 & 98 & 37.60 \\
Driving too aggressively & 134 & 22.70 & 69 & 23.20 \\
Managing other devices while driving & 99 & 16.80 & 58 & 19.50 \\
Temperature is too high inside the car & 28 & 4.70 & 18 & 6.00 \\
Smoking while driving & &
\end{tabular}

Additionally noteworthy is the case of the notification of fatigue that is associated with the age and gender of the drivers. More than $70 \%$ of those over the age of 41 prefer to be notified about this aspect, compared to $57 \%$ of those under the age of 40 . This may be due to the greater confidence that young people have in their physical abilities, which reduces their perception of the danger of driving with fatigue. In the case of gender, women who do not have ADAS prefer to be notified of fatigue in $56 \%$ of cases compared to $67 \%$ of men. Similar gender differences also appear in drivers with ADAS: $56 \%$ of women versus $74 \%$ of men.

\subsubsection{Information about the Weather}

Analyzing the preferences of drivers about the information related to the weather that they would like to receive through the assistant, all drivers (with and without ADAS) would like to receive information on all aspects related to the weather that have been considered, especially on the presence of ice sheets on the road. This result is logical, since the presence of sheets of ice is the most dangerous weather factor for driving and notifications of the presence of ice could be decisive to avoid serious accidents. Likewise, the notification of ice presents significant differences depending on the country ( $p$-value $<0.001$ ), both for users without ADAS and with ADAS. Thus, in Spain, $89 \%$ would like to receive this information, compared to $69 \%$ in Portugal. This discrepancy in valuation may be due to geographical and climatic differences between the two countries as icy conditions are more frequent and dangerous on the roads of northern Spain. 


\subsubsection{Relaxation Method with Stress}

All participants (with and without ADAS) prefer to listen to music (70\%) as a method to reduce stress, followed by breathing control and prefer to be reminded when they are suffering from stress. In the case of ADAS users, there is an association with the country ( $p$-value $=0.01)$, with a greater preference for listening to music in Portugal $(83.6 \%)$ than in Spain $(69.9 \%)$.

\subsubsection{Method to Avoid Distractions}

The answers to the question "What helps you avoid distractions the most" are indicated in Table 8. There is also a match between users with and without ADAS about the preferred method to avoid distractions, in both cases they prefer to listen to music. There are significant differences according to gender, similar to those with or without ADAS. $41 \%$ of women prefer to listen to music compared to $32 \%$ of men. In addition, for drivers without ADAS there are differences by age. Thus, $43 \%$ of drivers under 40 prefer to listen to music and only $10 \%$ prefer to listen to radio programs, compared to $21 \%$ of other age groups. For users of ADAS there are differences according to the country of the respondents. In Portugal, $49.1 \%$ prefer to listen to music while in Spain only $31.7 \%$, the preferred option in Spain being to listen to radio programs (34.2\%). There is also an association by age for users of ADAS. Drivers under 40 prefer to listen to music (45.4\%) rather than radio programs $(19.4 \%)$ while the preference of those over 60 is exactly the opposite: listen to radio programs $(40.0 \%)$ and music $(20.0 \%)$.

Table 8. Responses of the participants referring to the preferred method to avoid distractions.

\begin{tabular}{lcccc}
\hline \multirow{2}{*}{$\begin{array}{l}\text { Information Provided by ADAS } \\
\text { Listen to music }\end{array}$} & \multicolumn{2}{c}{$\begin{array}{c}\text { Respondents without } \\
\text { ADAS (N = 590) }\end{array}$} & \multicolumn{2}{c}{$\begin{array}{c}\text { Respondents with } \\
\text { ADAS (N = 298) }\end{array}$} \\
\cline { 2 - 5 } & $\mathbf{n}$ & $\mathbf{\%}$ & $\mathbf{n}$ & $\mathbf{\%}$ \\
\hline Do not listen to anything & 217 & 36.8 & 104 & 34.90 \\
To be reminded how important it is to & 177 & 30.0 & 64 & 21.50 \\
stay alert & 99 & 16.8 & 38 & 12.80 \\
Listen to radio programs & 97 & 16.4 & 92 & 30.90 \\
\hline
\end{tabular}

\subsubsection{Drowsiness Aid Method}

The analysis of the answers about the method that helps most when feeling sleepy indicates that, practically $50 \%$ of all drivers prefer to drink a caffeinated beverage to fight sleepiness. Other options, in order of preference, are listening to music, listening to radio programs, being reminded of how important it is to stay alert and not listening to anything.

\subsection{Method of Receiving Information}

The answers to the question "By what method would you like to receive information from your assistant?" are indicated in Table 9. Both users of ADAS and those who do not have one mostly prefer ( $89 \%$ ) to receive audio notifications over the other means of warning notification. There is an association by country for visual notifications, the preference of this option being higher in Portugal than in Spain. There is also an association by gender, with $37.4 \%$ of men and $19.0 \%$ of women preferring visual notification. 
Table 9. Responses of the participants referring to the preferred method to be notified by ADAS.

\begin{tabular}{lcccc}
\hline \multirow{2}{*}{ Information Provided by ADAS } & \multicolumn{2}{c}{$\begin{array}{c}\text { Respondents without } \\
\text { ADAS (N = 590) }\end{array}$} & \multicolumn{2}{c}{$\begin{array}{c}\text { Respondents with } \\
\text { ADAS (N = 298) }\end{array}$} \\
\cline { 2 - 5 } & $\mathbf{n}$ & $\mathbf{\%}$ & $\mathbf{n}$ & $\mathbf{\%}$ \\
\hline Audio notification & 522 & 88.5 & 267 & 89.60 \\
Through vibrations in the safety belt & 80 & 13.6 & 46 & 15.40 \\
Visual notification & 19 & 20.2 & 89 & 29.90 \\
\hline
\end{tabular}

\subsubsection{Use of Avatar}

The answers referred to determine if the use of a virtual friend (avatar) would be more friendly than a simple recommendation message indicate no differences in all the considered cases. In fact, the valuation percentages of receiving notifications through a message or through an avatar are similar.

\subsubsection{Type of Avatar}

In general, there is no special predilection for the type of avatar that would be more user-friendly (a cartoon character, a symbol, an image of a driver). However, in the case of users of ADAS there is an association with the country of the respondents. Thus, in the case of Spain, the most chosen option is "Have no special preference" $(60.9 \%)$ while in Portugal "a cartoon" (41.8\%) is preferred.

\subsubsection{Gender of the Avatar Character}

The majority of the respondents claim that they have no special preference for the gender of the avatar character with whom they interact ( $71 \%$ of the respondents). However, there is a clear preference for the feminine gender over the masculine. In the case of drivers without an assistant, there are significant differences in terms of gender. A total of $19.78 \%$ of men prefer a female avatar versus $10.67 \%$ of women. There is also an association with the country in the case of users of ADAS. In Portugal, $40.0 \%$ of respondents prefer a female gender avatar compared to $17.7 \%$ in Spain. There are also significant differences by gender for drivers with ADAS. $31 \%$ of men prefer a female avatar versus $10 \%$ of women.

To date, the analysis has been carried out on some of the most relevant questions of the survey that will allow us to draw important conclusions about what the usefulness and functionality provided by an ADAS should be, as well as aspects related to its interaction. In the next section, we will cross-examine issues related to behavior while driving and what drivers expect from an ADAS, so we can infer some information not provided directly by the answers, but which is very relevant in the pursuit of an efficient design of the ADAS.

\subsection{Analysis of Driver Behavior and Driver Preferences for the Assistant}

In this section, we will analyze the relationships between the behavior of the driver and their preferences for the design of the assistant.

3.6.1. Relationship between Being Distracted Frequently When Driving and What Helps You Avoid Distractions

This analysis aims to discover the relationship between the questions "Are you frequently distracted while driving?" and "What helps you avoid distractions the most?". The results are indicated in Table 10. 
Table 10. Frequency of distractions while driving vs. method to avoid distractions ( $p$-value $=0.001$ ).

\begin{tabular}{lcccc}
\hline & Listen to Music & $\begin{array}{c}\text { Listen to Radio } \\
\text { Programs }\end{array}$ & $\begin{array}{c}\text { Do Not Listen } \\
\text { to Anything }\end{array}$ & $\begin{array}{c}\text { Be Reminded of } \\
\text { How Important } \\
\text { It Is to Be Alert }\end{array}$ \\
\hline Very frequent & $33.33 \%$ & $33.33 \%$ & $33.33 \%$ & 0 \\
Quite frequent & $25.93 \%$ & $19.75 \%$ & $20.99 \%$ & $33.33 \%$ \\
Infrequent & $36.38 \%$ & $21.54 \%$ & $27.37 \%$ & $14.70 \%$ \\
Rare & $41.88 \%$ & $20.51 \%$ & $29.91 \%$ & $7.69 \%$ \\
\hline
\end{tabular}

The Fisher test, being $p$-value $<0.05$, indicates association between the frequency of distractions and the preferred method to avoid them. The survey data show surprising results. Those who are distracted very frequently do not want to be reminded of the importance of staying alert, while for those who are distracted quite frequently this is the most demanded method (33\%). In addition, for those who are not usually distracted by anything or seldom distracted, the preferred method is to listen to music.

3.6.2. Relationship between Circumstances on Long Journeys and Situations That Can Represent Some Danger on the Road

In this section, the goal is to determine which help method drivers prefer to avoid distractions, drowsiness or help them relax when they are stressed on long trips, situations which can often lead to an accident. It is interesting to note that, given the question of whether drivers get distracted while driving, 13\% answered that they never did and $77 \%$ only rarely, leaving only $10 \%$ who answered 'sometimes'. Then, we consider the behavior of drivers on long trips and what helps them avoid distractions based on their profile. The results are shown in Figure 1 (Questions: "On long trips, you are more likely to...?" and "What helps you avoid distractions the most?"), where it is possible to see that most drivers choose to listen to music on long trips. Excluding drivers who claim to feel good throughout the trip, the following risk factors are drowsiness, stress and distraction.

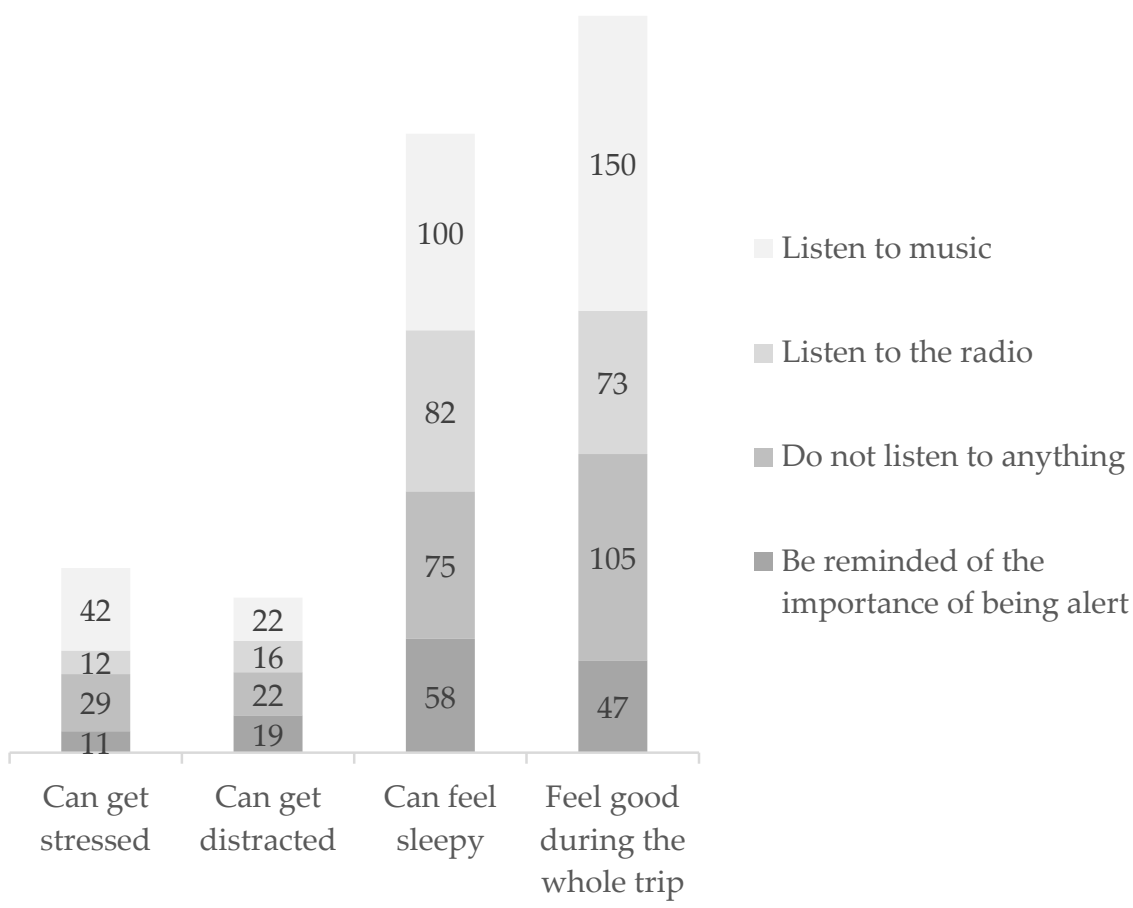

Figure 1. How drivers prefer the assistant on long trips, based on their profile while driving.

Additionally, data from the survey show drivers who feel sleepy on long trips mostly prefer $(57 \%)$ the option of drinking a caffeinated beverage. In addition, those who are 
stressed on long trips mostly prefer $(71 \%)$ to listen to music to relax, compared to other options such as controlling their breathing or warning them that they are stressed. On the other hand, the information that the driver would like to receive about the weather may be related to the level of stress involved when driving in adverse weather conditions (Questions: "How much does driving in the rain/snow/icy conditions stress you?"). Thus, the degree of stress when driving in rain, snow or sheets of ice has been compared with information on the weather that the driver wants to receive from the ADAS (Question: "Which of the following information regarding the weather would you like to receive from the assistant?", "Dangerous weather conditions in the next few minutes", "There are icy patches on the road", "There are areas of fog further ahead"). The results are indicated graphically in Figure 2.

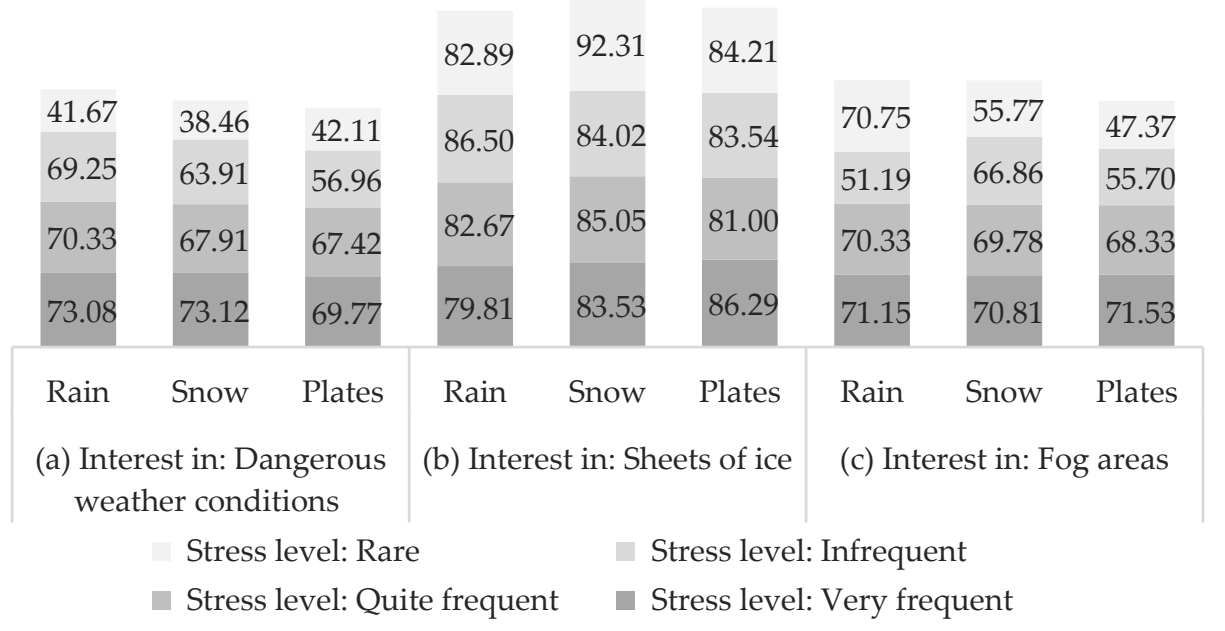

Figure 2. Analysis of weather-related stress and weather information wanted by drivers: (a) Interest in: dangerous weather conditions; (b) Interest in: sheets of ice; (c) Interest in: fog areas.

Interesting conclusions are obtained analyzing the results of Figure 2. On the one hand, the vast majority of drivers (more than $80 \%$ in all cases), regardless of the degree and type of weather-related stress, want to be notified of the presence of sheets of ice on the road. These results are consistent with those obtained in Section 3.4.4, which highlights the danger of icy conditions on the roads and the importance that drivers give to these warnings. On the other hand, there is an association $(p$-value $<0.05)$ between the notifications of "dangerous weather conditions" and "areas of fog further along the road" and the degree of stress manifested by the respondents. Thus, the greater the degree of stress with the different weather adversities, the higher the percentage of those who want to be notified of those circumstances.

\subsection{Discussion}

This section presents a summary of several criteria for defining an ADAS, based on user preferences that we have gathered and shown in previous sections. In Tables 11 and 12, we present the most relevant criteria that should be taken into account in the design of an ADAS, the most chosen option and differentiation, when applicable, based on age, gender and country, and whether it refers to a driver who has already used an assistant. 
Table 11. Summary of driver's preferences regarding usefulness.

\begin{tabular}{|c|c|c|}
\hline Criteria & Main Option & Differentiation \\
\hline $\begin{array}{l}\text { General usefulness of an } \\
\text { assistant }\end{array}$ & $\begin{array}{l}\text { Very useful, in more than } 90 \% \text { of } \\
\text { cases, in drivers with and } \\
\text { without ADAS }\end{array}$ & $\begin{array}{l}\text { By age: for drivers without an assistant, there is less awareness of } \\
\text { usefulness for those over the age of } 60 \text {. } \\
\text { By gender: women surveyed that use assistants give them more } \\
\text { importance than men when driving through unfamiliar areas. }\end{array}$ \\
\hline $\begin{array}{l}\text { What can be improved } \\
\text { on an ADAS? }\end{array}$ & $\begin{array}{l}\text { System interaction and } \\
\text { notifications }\end{array}$ & $\begin{array}{l}\text { Interaction with the system: } \\
\text { By age: the younger group is critical compared to the other age } \\
\text { groups, regarding the graphics and the interaction component with } \\
\text { the system. } \\
\text { By gender: men give more value to the graphic part than women. }\end{array}$ \\
\hline
\end{tabular}

Table 12. Summary of drivers' preferences regarding design preferences.

\begin{tabular}{lll}
\multicolumn{1}{c}{ Criteria } & \multicolumn{1}{c}{ Main Option } & Differentiation \\
\hline $\begin{array}{l}\text { When do drivers want to } \\
\text { receive notifications? }\end{array}$ & $\begin{array}{l}\text { Only when there is something relevant } \\
\text { to report. They do not want periodic or } \\
\text { programmable notifications. }\end{array}$ & \\
\end{tabular}

\author{
How do drivers want to \\ receive notifications?
}

With an audio notification

Approaching an accident; Approaching a traffic jam; Driving in the wrong direction; General weather conditions especially ice; When they start to get tired, when they exceed the maximum speed
In Portugal there is more interest in knowing when driving aggressively, compared to Spanish drivers (51\% versus $29 \%$ ). Additionally, in terms of information on air quality, the Portuguese are more interested in this information $(60 \%$ against $33 \%)$. Information on tiredness is more important for people over $40(70 \%)$ than below this age $(57 \%)$. Regarding fatigue, women give it less importance $(56 \%)$ than men $(67 \%)$. As regards ice on the road, Spanish drivers give more importance to this information (89\%) compared to the Portuguese (69\%).

What they do not want to be informed about

When they are smoking.

In Portugal this preference is more pronounced (84\%) than in Spain $(70 \%)$.

In drivers without assistants, the $\%$ of music choice is higher for women (41\%) than men (32\%). Those under

Preferential form of relaxation
Listen to music 40 prefer to listen to music ( $43 \%$ ) and only $10 \%$ radio. In Portugal, the option "listen to music" is more relevant $(49 \%)$ than in Spain (31\%), where the most relevant is radio (34\%). Users of ADAS under 40 prefer to listen to music $(45 \%)$ rather than radio whilst with users over the age of 60 it is just the opposite.

For the audio notifications there is no differentiation. There is an association by country and by gender for visual notifications, being higher in Portugal than in Spain and in men $(37.4 \%)$ than in women $(19.0 \%)$.
Preferential form of notification in case of distraction

Preferred way to avoid drowsiness

Audio notifications

Drink caffeinated beverages

Overall, there is no preference for a

Use of avatar more user-friendly avatar in relation to a message, either in relation to the avatar image or its gender
In drivers with assistants, in Portugal they prefer a cartoon $(41 \%)$ while in Spain they have no preference (61\%). Regarding gender, there is a strong preference for a female avatar, more chosen by men than women, regardless of being or not users of ADAS. In users of ADAS, there is a greater preference for a female avatar in Portugal (40\%) than in Spain (18\%). 
Regarding driver behavior and driver preferences, the analysis allows to conclude that, while driving, drivers can be distracted, be overly stressed and sleepy. For these cases, the action of the driving assistant can be of great help to mitigate these effects. In these cases, actions such as reminders to stay alert, turn on the radio or play music can help make driving safer. Likewise, driving in adverse weather conditions can be a cause of stress for drivers, decreasing their ability to drive safely. In these cases, the assistant's notifications about the existence of adverse conditions could help mitigate the stress of the driver. From the analysis of drivers' preferences, although all the notifications are significant for improved driving, great importance is given by the respondents to being notified of icy patches and it is worth highlighting the relationship between the degree of stress and the requirement of notifications of adverse weather conditions.

\section{Prototype}

\subsection{Overview}

As stated in Section 2, the existing ADASs fail to consider all of the factors which affect driving behavior. Therefore, we aim for the creation of a system that considers all the factors mentioned: driver's mood and biometric measurements, cabin characteristics and vehicle monitorization, so we can also test the results obtained in the survey. At this stage, this is still a prototype in development for research purposes and, therefore, it cannot be compared with the ones from real car manufacturers. Our goal is to prove that it is possible and interesting to create an advanced system capable of assisting, advising and motivating the driver without affecting the vehicle's cost, making a positive impact in the driving process. In the future, this service could even be implemented in the CarPC itself to obtain the data from automotive-grade sensors, which would make it even easier to integrate in the vehicle.

We have designed and implemented the prototype taking into account the user's preferences. The proposed system collects data from different sensors installed in the cockpit and also from the On-Board Diagnostic version 2 (OBD-II) of the vehicle, which monitors the speed, throttle position and rpms. The data collected by the sensors are temperature, humidity, pressure, light, air quality, noise and GPS information (speed, latitude, longitude, altitude). We have also included a sensor to collect biometric information from the driver using a heart rate monitor. In addition, from the GPS position values, the system connects with Internet services that provide the name of the road such as the type (motorway, urban ... ), number of lanes, maximum speed, etc., as well as weather conditions in the specific location. The real-time information gathered from the sensors and the OBD-II is processed, detecting driving patterns and different events to be considered. Then, using an expert system, recommendations are generated based on the information collected and analyzed in conjunction with the driver model and the road context, triggering status updates which feed the system. These recommendations are visually projected on an interface accompanied by an avatar, specifically designed for this ADAS prototype by a graphic designer. In addition, according to the preferences of the users, sound notifications are also included.

\subsection{Architecture}

Figure 3 shows the architecture of the developed prototype. When the vehicle starts, the assistant contacts with the central system and updates the base for the driving status, the driver model and the rules set. All the elements are produced in the central system using machine-learning processes and are loaded in the expert system engine designed for low resource systems. 


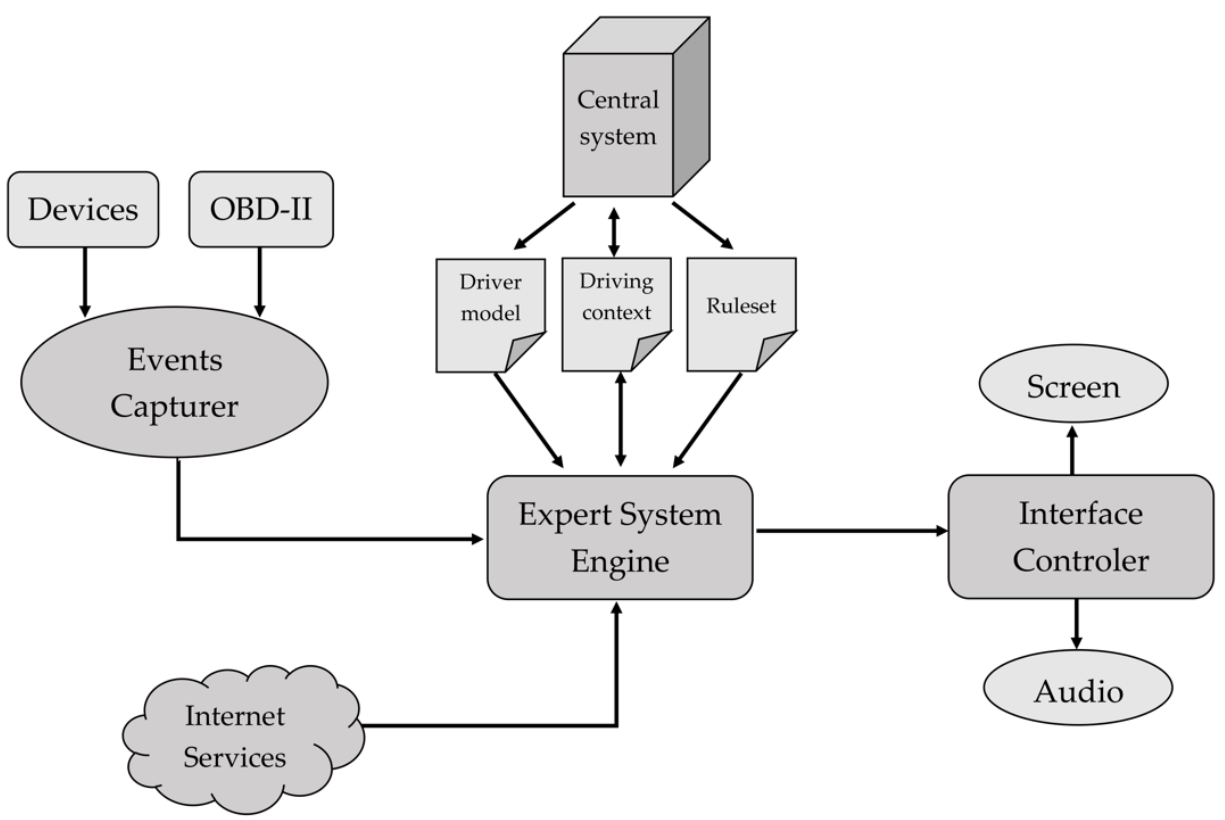

Figure 3. Architecture of the ADAS prototype.

The driver model includes general characteristics of the driver such as gender, age, biometric info, mean value of heart rate driving in different situations, as well as their preferences (if they enjoy driving or listening to loud music, if they get stressed easily or even if they tend to suffer drowsiness), driving profile information (e.g., aggressive) and several data drawn from previous behaviors such as usual journeys or if they typically drive on motorways, urban or suburban roads. Some information on the type of car is also included, such as the type of vehicle, the fuel that it uses or the transmission (manual or automatic).

As for the driving status, it stores data such as the duration and the time of the day of the current and previous trip, the driver's mood, the rest between trips, the frequency of sudden accelerations and braking, the current location and the weather.

A knowledge base is created at the beginning of each trip, which includes the driver model and the driving status. It obtains the data of the last trip and begins to detect events and patterns of the current one that indicate a change in the behavior or driving conditions, triggering the rules set which updates the status, offering feedback. Whenever that happens, the system generates the necessary messages for the driver through audio and visual notifications in order to change their actions or motivate them.

\subsection{Technologies}

The prototype has been developed using a Raspberry-Pi to create an embedded device and the different sensors are connected to a printed circuit board, as shown in Figure 4. The local storage system for the data collected (by the sensors and through the vehicle's OBD-II port) is based on SQLite, which helps not to overload the system. Data capture and storage is carried out every $0.5 \mathrm{~s}$. As for the rule system, it is developed in Python using the engine provided by durable-rules (https://pypi.org/project/durable-rules/, accessed on 30 March 2021) to analyze the events and generate the response of the system accordingly. The graphic interface was implemented using the library provided by Tkinter, and the audio using Pygame. The knowledge base consists of a dictionary that contains both the driving status and the driver model so that it can be easily accessed. 


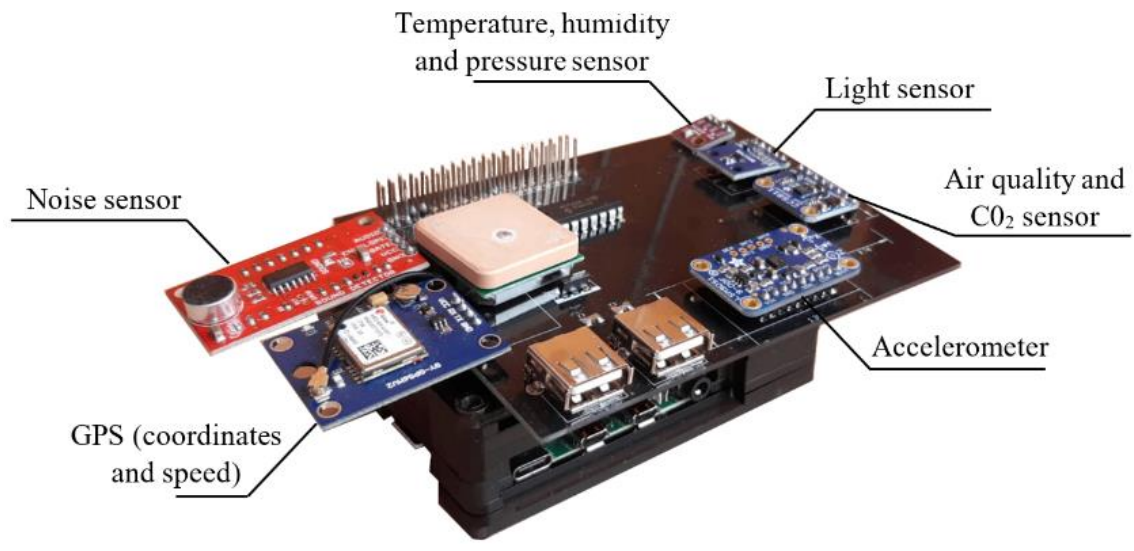

Figure 4. Raspberry-Pi connected to the PCB containing all the sensors.

Python Overpass (OverPy) was used for the road information through the GPS coordinates. It allows to request information on the roads and their characteristics surrounding a specific GPS location. It provides data such as the type, number of lanes, maximum speed, surface type, etc. The Open Weather API is the chosen method to obtain the weather conditions. From a set of coordinates, it offers information regarding the weather conditions, temperature (maximum, minimum, what it feels like), humidity, pressure, wind or even the sunrise and sunset time.

\subsection{Test Scenarios}

The prototype has been tested in a real environment where the sensors and the screen have been installed in a private vehicle. Then, different routes were made in an urban area, under different environmental conditions to check the operation of the rule system.

Table 13 presents a set of examples of the events and recommendations generated by the rules system. The parameters considered are selected only for demonstration purposes, since the variables will be generated and updated by the central system according to the specific driver. In Figure 5, two examples of the messages presented by the interface are shown. The rules take into account basic characteristics of the driver and the driving status to make recommendations of actions that would improve safety, comfort and focus.

To complete the evaluation of the real system, we have carried out performance tests where we obtained a CPU and memory consumption of $1.7 \%$ and $1.3 \%$, respectively, in the worst case. With these results we can conclude that the consumption of system resources is very low for the use cases tested.

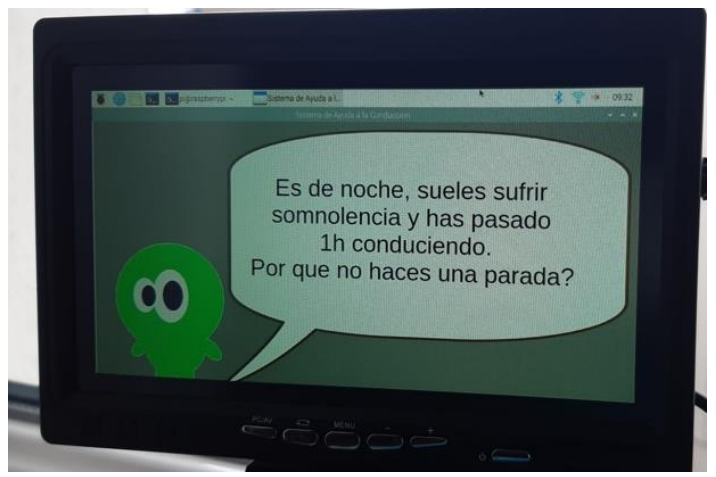

(a)

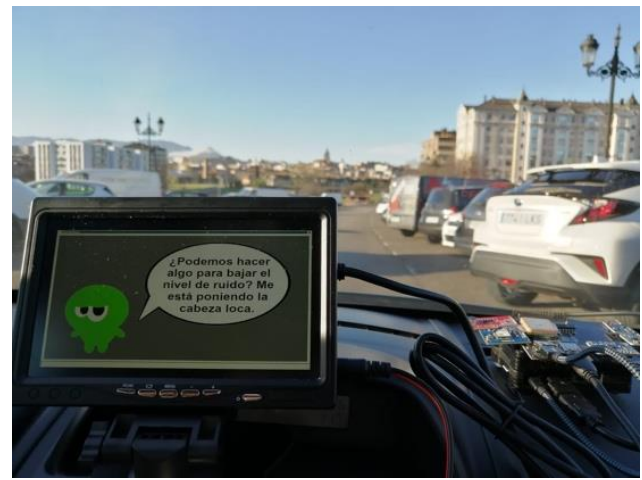

(b)

Figure 5. Different driving events and the generated alerts in the prototype. (a) Driver model: frequent drowsiness (b) Driver model: does not enjoy loud music, tends to suffer stress. 
Table 13. Examples of events and recommendations in the ADAS prototype.

\begin{tabular}{|c|c|c|}
\hline Event & Rule & Recommendation \\
\hline \multirow{3}{*}{ Tiredness detected } & $\begin{array}{l}\text {-Driver model: frequent drowsiness, enjoys driving } \\
\text {-Driving status: daytime, } 2 \mathrm{~h} \text { travelled }\end{array}$ & $\begin{array}{l}\text { "It has already been } 2 \mathrm{~h} \text {. Why don't you take } \\
\text { a break?" }\end{array}$ \\
\hline & $\begin{array}{l}\text {-Driver model: frequent drowsiness } \\
\text {-Driving status: night-time, } 1 \mathrm{~h} \text { travelled }\end{array}$ & $\begin{array}{l}\text { "It is night-time, you tend to suffer from } \\
\text { drowsiness, and it has been } 1 \mathrm{~h} \text {. Why don't } \\
\text { you take a break?" (Figure 5a) }\end{array}$ \\
\hline & $\begin{array}{l}\text {-Driver model: infrequent drowsiness, enjoys driving } \\
\text {-Driving status: daytime, } 3 \mathrm{~h} \text { travelled }\end{array}$ & $\begin{array}{l}\text { "You should take a break even if you don't } \\
\text { feel tired. It has been } 3 \text { h." }\end{array}$ \\
\hline High noise detected & $\begin{array}{l}\text {-Driver model: does not enjoy loud music, tends to } \\
\text { suffer stress } \\
\text {-Driving status: high noise }\end{array}$ & $\begin{array}{l}\text { "Could you turn the music down? It is too } \\
\text { loud" (Figure 5b) }\end{array}$ \\
\hline \multirow[t]{2}{*}{ First trip of the day } & $\begin{array}{l}\text {-Driver model: gets distracted easily, does not } \\
\text { enjoy driving } \\
\text {-Driving status: early in the morning, more than } 8 \mathrm{~h} \\
\text { since last trip, bad weather }\end{array}$ & $\begin{array}{l}\text { "Welcome. We have many hours ahead of us } \\
\text { and the weather seems to be bad. Today we } \\
\text { need to focus." }\end{array}$ \\
\hline & $\begin{array}{l}\text {-Driver model: enjoys driving } \\
\text {-Driving status: early in the morning, more than } 8 \mathrm{~h} \\
\text { since last trip, good weather }\end{array}$ & $\begin{array}{l}\text { "Welcome. It is a nice day to be driving, } \\
\text { don't you think? Let's go!" }\end{array}$ \\
\hline High stress detected & $\begin{array}{l}\text {-Driver model: tends to suffer stress and does not } \\
\text { enjoy driving } \\
\text {-Driving status: night-time, high heart rate, driving on } \\
\text { a motorway, frequent accelerations and braking }\end{array}$ & $\begin{array}{l}\text { "Is everything ok? I'm detecting stress, it is } \\
\text { night-time and your behavior is erratic. Shall } \\
\text { we take a break?" }\end{array}$ \\
\hline
\end{tabular}

\section{Discussions and Conclusions}

This paper presents the results of an extensive survey regarding drivers in Spain and Portugal with the objective of discovering the aspects that influence more significantly in driving and the functionalities that drivers consider important to be included in a driving assistant. For this purpose, we designed a survey that was answered by 888 drivers, and that was classified into 8 sets according to the topic they address: characteristics of the drivers, work-related stress, driver lifestyle, vehicle features and main use, driving behavior, driving distractions, driving stress and driving assistant.

Existing ADAS consider only basic aspects related to driving safety and efficiency and do not take into account all the information included in this study. Thus, the survey carried out with drivers of varied characteristics seeks to ascertain which aspects can improve the design and performance of the driving assistants. In the survey, main risk situations and different alternatives on how to alert the driver have been studied. Not only have individual aspects been considered, but different combinations of factors have also been analyzed and correlated in order to find dependencies to determine a set of intelligent rules to optimize the performance of ADAS.

This work has demonstrated that the personal characteristics of the driver (mood, fatigue and stress), combined with other elements of the driving context (road conditions, traffic, weather, cabin conditions) and data on the vehicle mechanics clearly influence the recommendations to be provided by the assistant. All these aspects are not included in commercial solutions and have not been considered in the related work. The analysis carried out on some of the most recent studies on ADAS has concluded that none of them consider all the variables we have included in our study. From the point of view of the parameters considered, [16] is the most complete and comprehensive study we found, taking into account factors of a different nature (driver, road, weather and vehicle). However, the authors do not explore the rules that affect the recommendations to the driver. Regarding commercial solutions, vehicle manufacturers are incorporating driving assistants focused on safety and fuel consumption, but they make a very limited use of information about the driver's state and preferences, or the vehicle cabin. 
We have considered, whenever applicable, differences in age, gender and country in the preferences for the ADAS. Regarding usefulness, we found that in more than $90 \%$ of cases, drivers find an ADAS very useful and also found some associations by age and gender. Among the information drivers want to be notified about, the following are included: approaching an accident; approaching a traffic jam; driving in the wrong direction; general adverse weather conditions, especially ice; when starting to get tired, when exceeding the speed limit. Conversely, drivers do not want to be notified when they are smoking. Listening to music is the most preferred form of relaxation and drinking a caffeinated beverage is the chosen method to fight drowsiness.

This study has confirmed that, although ADASs are not as popular as would be desirable, they are generally considered very useful, especially by young people and while driving on unknown roads. However, they are in need of major changes in order to gain acceptance, improving the quality of the assistance in terms of how and what the system gives information about. With all of this in mind, we have proposed a low-cost and minimally invasive prototype that considers not only the external data, but also the driver's characteristics and emotional state. Thanks to various sensors placed in the car and on the driver, as well as communication with Internet services and a previous analysis of the driver's profile, the recommendations are adapted to the specific circumstances of each trip and person. The main contribution of the proposed ADAS prototype is the intelligence rule system designed. The real-time recommendations shown to the drivers are based on a complex set of rules that take into account all the collected information.

Future steps include refining the particularization of the recommendations and increasing the number of driver's features to be considered and analyzed. In addition, it would be interesting to include remote processing of the data gathered during each trip in order to allow the system to be updated automatically, recognizing driving patterns and sequences based on the detected behavior. By doing so, a greater number and more specific recommendations can be included. Notifications through seat belt vibration in critical events could also be incorporated. In addition, more evaluation tests in real environments should be carried out. Finally, the impact ADAS recommendations can have on traffic congestion could be studied in more depth, considering the direct influence the driver behavior has on the traffic conditions. In this way, it will be possible to map the user's behavior with the state of the traffic and how changes in the way of driving can represent a decrease in the number of accidents as well as in situations of congestion.

Author Contributions: Conceptualization, S.P., X.G.P. and V.C.; methodology, X.G.P., C.d.C. and R.G.; validation, X.G.P. and R.G.; formal analysis, S.P., V.C. and R.G.; investigation, V.C., P.M. and C.d.C.; resources, X.G.P., L.P. and M.V.; data curation, V.C. and R.G.; writing-original draft preparation, S.P. and R.G.; writing - review and editing, L.P., M.V. and P.M.; visualization, all authors; funding acquisition, X.G.P. and R.G. All authors have read and agreed to the published version of the manuscript.

Funding: This research was funded by the Spanish National Research Program, grant number TIN2017-82928-R.

Institutional Review Board Statement: Not applicable.

Informed Consent Statement: Not applicable.

Data Availability Statement: The data presented in this study are available in Open Science Framework (OSF) at doi:10.17605/OSF.IO/K8GM5.

Acknowledgments: The authors wish to express their gratitude to the Statistical Consulting Section of the University of Oviedo for their support in the statistical treatment of the data used in this article.

Conflicts of Interest: The authors declare no conflict of interest. The funders had no role in the design of the study; in the collection, analyses or interpretation of data; in the writing of the manuscript, or in the decision to publish the results. 


\section{References}

1. Andria, G.; Attivissimo, F.; Di Nisio, A.; Lanzolla, A.M.; Pellegrino, A. Design and implementation of automotive data acquisition platform. In Proceedings of the IEEE International Instrumentation and Measurement Technology Conference (I2MTC), Pisa, Italy, 11-14 May 2015; pp. 272-277.

2. Wittmann, M.; Lohrer, J.; Betz, J.; Jäger, B.; Kugler, M.; Klöppel, M.; Waclaw, A.; Hann, M.; Lienkamp, M. A holistic framework for acquisition, processing and evaluation of vehicle fleet test data. In Proceedings of the IEEE 20th International Conference on Intelligent Transportation Systems (ITSC), Yokohama, Japan, 16-19 October 2017; pp. 1-7.

3. Sieber, M.; Färber, B. Driver perception and reaction in collision avoidance: Implications for ADAS development and testing. In Proceedings of the IEEE Intelligent Vehicles Symposium (IV), Gothenburg, Sweden, 19-22 June 2016; pp. 239-245.

4. SAE International. Taxonomy and Definitions for Terms Related to Driving Automation Systems for On-Road Motor Vehicles, Ground Vehicle Standard J3016; SAE Mobilus: Warrendale, PA, USA, 2016.

5. Magaña, V.C.; Muñoz-Organero, M. Artemisa: A Personal Driving Assistant for Fuel Saving. IEEE Trans. Mob. Comput. 2016, 15, 2437-2451. [CrossRef]

6. Rojdestvenskiy, D.; Cvetković, M.; Bouchner, P. Real-time driver advisory system for improving energy economy based on advance driver assistant systems interface. In Proceedings of the Smart City Symposium Prague (SCSP), Prague, Czech Republic, 24-25 May 2018; pp. 1-6.

7. Saito, Y.; Itoh, M.; Inagaki, T. Driver Assistance System with a Dual Control Scheme: Effectiveness of Identifying Driver Drowsiness and Preventing Lane Departure Accidents. IEEE Trans. Hum. Mach. Syst. 2016, 46, 660-671. [CrossRef]

8. Zeng, S.; Li, J.; Jiang, L.; Jiang, J. A driving assistant safety method based on human eye fatigue detection. In Proceedings of the 29th Chinese Control and Decision Conference (CCDC), Chongqing, China, 28-30 May 2017; pp. 6370-6377.

9. Quintero, M.C.; Cuervo, P.A. Intelligent driving assistant based on accident risk maps analysis and intelligent driving diagnosis. In Proceedings of the IEEE Intelligent Vehicles Symposium (IV), Los Angeles, CA, USA, 11-14 June 2017; pp. $914-919$.

10. Cheng, G.; Zheng, J.Y.; Murase, H. Sparse Coding of Weather and Illuminations for ADAS and Autonomous Driving. In Proceedings of the IEEE Intelligent Vehicles Symposium (IV), Changshu, China, 26-30 June 2018; pp. $2030-2035$.

11. Moten, S.; Celiberti, F.; Grottoli, M.; van der Heide, A.; Lemmens, Y. X-in-the-loop advanced driving simulation platform for the design, development, testing and validation of ADAS. In Proceedings of the IEEE Intelligent Vehicles Symposium (IV), Changshu, China, 26-30 June 2018; pp. 1-6.

12. Heckmann, M.; Orth, D.; Kolossa, D. Gap after the next two vehicles: A Spatio-temporally Situated Dialog for a Cooperative Driving Assistant. In Proceedings of the Speech Communication, 13th ITG-Symposium, Oldenburg, Germany, 10-12 October 2018; pp. 1-5.

13. Byon, Y.; Shalaby, A.; Abdulhai, B. Travel Time Collection and Traffic Monitoring via GPS Technologies. In Proceedings of the IEEE Intelligent Transportation Systems Conference, Toronto, ON, Canada, 17-20 September 2006; pp. 677-682.

14. You, C.; Lu, J.; Tsiotras, P. Nonlinear Driver Parameter Estimation and Driver Steering Behavior Analysis for ADAS Using Field Test Data. IEEE Trans. Hum. Mach. Syst. 2017, 47, 686-699. [CrossRef]

15. Lyu, N.; Duan, Z.; Xie, L.; Wu, C. Driving experience on the effectiveness of advanced driving assistant systems. In Proceedings of the 4th International Conference on Transportation Information and Safety (ICTIS), Banff, AB, Canada, 8-10 August 2017; pp. 987-992.

16. Yin, J.; Chen, B.; Lai, K.R.; Li, Y. Automatic Dangerous Driving Intensity Analysis for Advanced Driver Assistance Systems from Multimodal Driving Signals. IEEE Sens. J. 2018, 18, 4785-4794. [CrossRef]

17. Park, J.; Son, H.; Lee, J.; Choi, J. Driving Assistant Companion with Voice Interface Using Long Short-Term Memory Networks. IEEE Trans. Ind. Inform. 2019, 15, 582-590. [CrossRef]

18. Cheng, Z.; Jeng, L.; Li, K. Behavioral Classification of Drivers for Driving Efficiency Related ADAS Using Artificial Neural Network. In Proceedings of the IEEE International Conference on Advanced Manufacturing (ICAM), Yunlin, Taiwan, 16-18 November 2018; pp. 173-176.

19. Shouming, Q.; Liwei, H.; Xiaoyang, D. Control Methods of Traffic Congestion Based on Drivers' Behavior Characteristics. In Proceedings of the 8th International Conference on Intelligent Computation Technology and Automation (ICICTA), Nanchang, China, 14-15 June 2015; pp. 333-336.

20. Gheorghiu, R.A.; Cormos, A.C.; Iordache, V.; Alexandru, V. Analysis of driver behaviour's influence in urban traffic flows. In Proceedings of the 10th International Conference on Electronics, Computers and Artificial Intelligence (ECAI), Iasi, Romania, 28-30 June 2018; pp. 1-4.

21. Bevilacqua, C.; Bogdan, P.; Marculescu, R. Exploring congestion phase transitions in vehicular traffic via topology and driver behavior modeling. In Proceedings of the 2011 IEEE Forum on Integrated and Sustainable Transportation Systems, Vienna, Austria, 29 June-1 July 2011; pp. 115-121. [CrossRef]

22. Teoh, E.R. What's in a Name? Drivers' Perceptions of the Use of Five SAE Level 2 Driving Automation Systems. J. Saf. Res. 2020, 72, 145-151. [CrossRef]

23. ProPILOT 2.0—Next-Gen Driver Assistance System. Available online: https://global.nissannews.com/en/releases/propilot-20 (accessed on 19 February 2021). 
24. Nissan's "Driver Attention Alert" Helps Detect Erratic Driving Caused by Drowsiness and Inattention. Available online: https://usa.nissannews.com/en-US/releases/nissan-s-driver-attention-alert-helps-detect-erratic-driving-caused-bydrowsiness-and-inattention (accessed on 19 February 2021).

25. Neuhaus, R.; Laschke, M.; Theofanou-Fülbier, D.; Hassenzahl, M.; Sadeghian, S. Exploring the Impact of Transparency on the Interaction with an In-Car Digital AI Assistant. In Proceedings of the 11th International Conference on Automotive User Interfaces and Interactive Vehicular Applications: Adjunct Proceedings, Utrecht, The Netherlands, 22-25 September 2019; Association for Computing Machinery: New York, NY, USA, 2019; pp. 450-455.

26. Maag, C.; Muhlbacher, D.; Mark, C.; Kruger, H. Studying effects of advanced driver assistance systems (adas) on individual and group level using multi- driver simulation. IEEE Intell. Transp. Syst. Mag. 2012, 4, 45-54. [CrossRef]

27. Cao, S.; Qin, Y.; Jin, X.; Zhao, L.; Shen, M. Effect of driving experience on collision avoidance braking: An experimental investigation and computational modelling. Behav. Inf. Technol. 2014, 33, 929-940. [CrossRef]

28. Abe, G.; Richardson, J. The influence of alarm timing on driver response to collision warning systems following system failure. Behav. Inf. Technol. 2006, 25, 443-452. [CrossRef]

29. Park, E.; Kim, H.; Ohm, J.Y. Understanding driver adoption of car navigation systems using the extended technology acceptance model. Behav. Inf. Technol. 2015, 34, 741-751. [CrossRef]

30. Jimenez-Mejias, E.; Lardelli, P.; Amezcua-Prieto, C.; Jimenez Monlen, J.J. A review of questionnaires exploring driver's exposure and risk factors in road crashes. An. Sist. Sanit. Navar. 2011, 34, 443-452.

31. Jiménez Mejías, E.; Luna del Castillo, J.D.; Amezcua Prieto, C.; Olvera Porcel, M.C.; Lardelli Claret, P.; Jiménez Moleón, J.J. Diseño y validación de un cuestionario sobre patrones de conducción de riesgo en jóvenes. Rev. Española Salud Pública 2012, 86, 71-84. [CrossRef] [PubMed]

32. Owsley, C.; Stalvey, B.T.; Elgin, J.; Sloane, M. Older drivers and cataract: Driving habits and crash risk. J. Gerontol. Ser. A Biol. Sci. Med Sci. 1999, 54, M203-M211. [CrossRef] [PubMed]

33. De Winter, J.; Dodou, D. The driver behaviour questionnaire as a predictor of accidents: A meta-analysis. J. Saf. Res. 2010, 41, 463-470. [CrossRef]

34. Leandro, M. Tres instrumentos para el estudio de la conducta de conducir. In Psychology/Environmental PhD. Program; GSUC/CUNY: New York, NY, USA, 2009.

35. Ajzen, I. The theory of planned behavior. Organ. Behav. Hum. Decis. Process. 1991, 50, 179-211. [CrossRef]

36. Crawford, J.R.; Henry, J.D. The depression anxiety stress scales (dass): Normative data and latent structure in a large non-clinical sample. Br. J. Clin. Psychol. 2003, 42, 111-131. [CrossRef]

37. Hart, S.G.; Staveland, L.E. Development of nasa-tlx (task load index): Results of empirical and theoretical research. Adv. Psychol. 1988, 52, 139-183.

38. Pauzie, A. A method to assess the driver mental workload: The driving activity load index (dali). IET Intell. Transp. Syst. 2008, 2, 315-322. [CrossRef]

39. Shively, R.J.; Bortolussi, M.R.; Battiste, V.; Hart, S.G.; Pepitone, D.D.; Matsumoto, J. Inflight Evaluation of Pilot Workload Measures for Rotorcraft Research; International Symposium on Aviation Psychology: Columbus, OH, USA, 1987.

40. Milleville-Pennel, I.; Charron, C. Driving for real or on a fixed-base simulator: Is it so different? An explorative study. Presence Teleoper. Virtual Environ. 2015, 24, 74-91. [CrossRef]

41. Gde, M.; Trkulja, V.; Petras, V. Everything changes, everything stays the same? Understanding information spaces. In Proceedings of the 15th International Symposium of Information Science (ISI 2017), Berlin, Germany, 13-15 March 2017; Volume 24, pp. 116-130.

42. Lisetti, C.L.; Yasavur, U.; Visser, U.; Rishe, N. Toward conducting motivational interviewing with an on-demand clinician avatar for tailored health behavior change interventions. In Proceedings of the 5th International Conference on Pervasive Computing Technologies for Healthcare (PervasiveHealth) and Workshops, Dublin, Ireland, 23-26 May 2011; pp. $246-249$.

43. Nurgaliyev, K.; Mauro, D.D.; Khan, N.; Augusto, J.C. Improved multi-user interaction in a smart environment through a preference-based conflict resolution virtual assistant. In Proceedings of the 2017 International Conference on Intelligent Environments (IE), Seoul, Korea, 21-25 August 2017; pp. 100-107.

44. Konecki, M.; Gams, M.; Ivkovi, N. Mia: A multi-purpose intelligent assistant. In Proceedings of the 38th International Convention on Information and Communication Technology, Electronics and Microelectronics (MIPRO), Opatija, Croatia, 25-29 May 2015; pp. 1109-1113.

45. Lugano, G. Virtual assistants and self-driving cars. In Proceedings of the 15th International Conference on ITS Telecommunications (ITST), Warsaw, Poland, 29-31 May 2017; pp. 1-5.

46. Felnhofer, A.; Kaufmann, M.; Atteneder, K.; Kafka, J.X.; Hlavacs, H.; Beutl, L.; Hennig-Fast, K.; Kothgassner, O.D. The mere presence of an attentive and emotionally responsive virtual character influences focus of attention and perceived stress. Int. J. Hum. Comput. Stud. 2019, 132, 45-51. [CrossRef]

47. Alvarez, I.; Alnizami, H.; Dunbar, J.; Jackson, F.; Gilbert, J.E. Help on the road: Effects of vehicle manual consultation in driving performance across modalities. Int. J. Hum. Comput. Stud. 2015, 73, 19-29. [CrossRef]

48. Ho, C.; Spence, C. Assessing the effectiveness of various auditory cues in capturing a driver's visual attention. J. Exp. Psychol. Appl. 2005, 11, 157-174. [CrossRef]

49. Horowitz, A.D.; Dingus, T. Warning signal design: A key human factors issue in an in-vehicle front-to-rear-end collision warning system. Proc. Hum. Factors Soc. 1992, 36, 1011-1013. [CrossRef] 
50. Green, P.; Sullivan, J.; Tsimhoni, O.; Oberholtzer, J.; Buonarosa, M.; De-vonshire, J.; Schweitzer, J.; Baragar, E.; Sayer, J. Integrated Vehicle-Based Safety Systems (Ivbss): Human Factors and Driver-Vehicle Interface (dvi) Summary Report; National Highway Traffic Safety Administration: Washington, DC, USA, 2008.

51. Adell, E.; Varhelyi, A.; Alonso, M.; Plaza, J. Developing human-machine interaction components for a driver assistance system for safe speed and safe distance. IET Intell. Transp. Syst. 2008, 2, 1-14. [CrossRef]

52. Diederich, A.; Colonius, H. Bimodal and trimodal multisensory enhancement: Effects of stimulus onset and intensity on reaction time. Percept. Psychophys. 2004, 66, 1388-1404. [CrossRef] [PubMed]

53. Vahidi, A.; Eskandarian, A. Research advances in intelligent collision avoidance and adaptive cruise control. IEEE Trans. Intell. Transp. Syst. 2003, 4, 143-153. [CrossRef]

54. Avatar Replaces Vehicle Owner's Manual. Available online: https://www.isa.org/standards-and-publications/isa-publications / intech-magazine/2011/october/automation-update-avatar-replaces-vehicle-owners-manual/ (accessed on 23 February 2019).

55. The Irish Times, Ibm and Ucd in Drive to Perfect Intelligent In-Car Assistant. Available online: https:/ / www.irishtimes.com/ business/innovation/ibm-and-ucd-in-drive-to-perfect-intelligent-in-car-assistant-1.2966857?cm_mc_uid=1745935467581488 1263421\&cm_mc_sid_50200000=(accessed on 13 February 2019).

56. Rns 810. Available online: https://www.volkswagen.co.uk/technology/navigation-and-entertainment-systems/rns-810 (accessed on 10 October 2019).

57. Charamel, Avatar Service in Car Devices. Available online: https://www.charamel.com/en/case-studies/avatar-service-in-cardevices (accessed on 13 February 2019).

58. Pocket-Lint, an In-Car Avatar Becomes Your Ride-Along Assistant in Nissan's Invisible-to-Visible Driving Concept. Available online: https:/ / www.pocket-lint.com/cars/news/nissan/146615-an-avatar-becomes-your-assistant-in-nissan-invisibleto-visible-driving-concept (accessed on 13 February 2019).

59. Rohatgi, V.K.; Saleh, A.K. An Introduction to Probability and Statistics, 2nd ed.; Wiley Series in Probability and Statistics; John Wiley \& Sons: Hoboken, NJ, USA, 2015.

60. Son, J.; Park, M.; Park, B.B. The effect of age, gender and roadway environment on the acceptance and effectiveness of advanced driver assistance systems. Transp. Res. Part F Traffic Psychol. Behav. 2015, 31, 12-24. [CrossRef]

61. Bellet, T.; Paris, J.C.; Marin-Lamellet, C. Difficulties experienced by older drivers during their regular driving and their expectations towards advanced driving aid systems and vehicle automation. Transp. Res. Part F Traffic Psychol. Behav. 2018, 52, 138-163. [CrossRef]

62. Weiss, E.; Thiel, M.F.; Sultana, N.; Hannan, C.; Seacrist, T. Advanced driver assistance systems for teen drivers: Teen and parent impressions, perceived need, and intervention preferences. Traffic Inj. Prev. 2018, 19, S120-S124. [CrossRef]

63. Oxley, P.R.; Mitchell, C.G. Final Report on Elderly and Disabled Drivers Information Telematics. Dedicated Road Infrastructure for Vehicle Safety in Europe Drive ii Project v2031 Elderly and Disabled Drivers Information Telematics Eddit, Deliverable Type p. $r$ d Programme Telematics System in the Area of Transport (Drive ii); Commission of the European Communities CEC, Directorate General XIII Telecommunications, Information Industries and Innovation: Brussels, Belgium, 1995.

64. Stevens, S. The relationship between driver acceptance and system effectiveness in car-based collision warning systems: Evidence of an overreliance effect in older drivers? SAE Int. J. Passeng. Cars Electron. Electr. Syst. 2012, 5, 114-124. [CrossRef]

65. Viborg, N. Older and younger drivers attitudes toward in-car its. Bulletin 1999, 181, 1-20. 